\title{
LA PRESIDENCIA DE LAS ASAMBLEAS DE LAS DICTADURAS EN LA EUROPA DEL SUR ${ }^{1}$
}

\section{THE PRESIDENCY OF THE ASSEMBLIES OF THE SOUTHERN EUROPEAN DICTATORSHIPS}

\author{
Mikel Urquijo \\ Universidad del País Vasco
}

\begin{abstract}
SUMARIO: I. INTRODUCCIÓN.- II. LAS ASAMBLEAS DE LAS DICTADURAS.- III. LA REGULACIÓN DE LA PRESIDENCIA DE LAS ASAMBLEAS DE LAS DICTADURAS.- IV. LOS PRESIDENTES DE LAS ASAMBLEAS DE LAS DICTADURAS.- V. CONCLUSIONES.
\end{abstract}

Resumen: El objeto de este artículo es contribuir al debate sobre el sentido de las asambleas de las dictaduras del sur de Europa en el siglo XX a través del estudio de la presidencia de las mismas en España (1943-1977), Italia (1924-1943) y Portugal (1935-1974). Para ello vamos a examinar el procedimiento de nombramiento de los presidentes, clasificar las funciones que desempeñaba la presidencia y en realizar un análisis prosopográfico de las personas que desempeñaron esta responsabilidad, comparándolas con la presidencia de los parlamentos democráticos que se crearon en estos mismos países tras el fin de las dictaduras.

Abstract: The aim of this article is to contribute to the debate on the significance of the parliamentary assemblies in Southern Europe in the XX century by studying the parliamentary speakership in Spain (1943-1977), Italy (1924-1943) and Portugal (1935-1974). To carry out this analysis we will study the procedure by which the speakers were appointed, clarify the functions they performed and conduct a prosopographical analysis of the individuals who held this post, comparing them with the speakership in the democratic parliaments that were created in the same countries after the dictatorships had ended.

Palabras clave: Parlamento, Presidencia, Dictadura, Democracia, Historia comparada.

Key Words: Parliament, Presidency, Dictatorship, Democracy, Comparative History.

\section{INTRODUCCIÓN}

El objeto de este artículo es contribuir al debate sobre el sentido de las asambleas de las dictaduras del sur de Europa en el siglo XX a través del estudio

\footnotetext{
1 Este trabajo ha sido realizado gracias al proyecto PGC2018-095712-B-100 financiado por el Ministerio de Ciencia, Innovación y Universidades (Gobierno de España).
} 
de su presidencia. Este trabajo se enmarca en una investigación más amplia sobre la presidencia del parlamento en España en la época contemporánea2 .

Tras la consolidación de los parlamentos liberales una ola de antiparlamentarismo recorrió Europa. En este proceso los regimenes dictatoriales de comienzos del siglo XX impusieron un tipo de asambleas que rompían con la tradición liberal anterior. Estas cámaras se crearon en buena parte de Europa en el periodo de entreguerras. Algunos ejemplos son los de Polonia, Bulgaria, Hungria, Austria, Yugoslavia, Italia, Portugal o España ${ }^{3}$. En el inicio de este trabajo nos preguntábamos si es posible comparar estas asambleas con los parlamentos liberales o democráticos en algún sentido. $O$ si debemos considerarlas como asambleas representativas de los regímenes dictatoriales o si simplemente eran cámaras de "eco do regime", como indica J.M. Tavares Castilho ${ }^{4}$ para Portugal.

Para aproximarnos al sentido de estas asambleas nuestra aportación se referirá al estudio de la presidencia de las mismas en Italia (1924-1943) ${ }^{5}$, Portugal (1935-1974) y España (1943-1977), comparándolas con la presidencia de los parlamentos democráticos que se crearon en estos mismos países a partir de 1946, 1975 y 1977, respectivamente y que suponen un claro contraste con las anteriores.

En este análisis nos vamos a centrar en el estudio del procedimiento de nombramiento de los presidentes, en la clasificación de las funciones que desempeñaba la presidencia y realizar un análisis prosopográfico de las personas

2 Hasta el momento hemos presentado la siguiente comunicación: Mikel Urquijo, "The Speakership of the Parliament in the Contemporary Spain (1810-1939)", CISH's XXIInd Congress (Jinan (China), 2015). Han sido aceptadas: Mikel Urquijo, "Prosopographical analysis of the parliamentary speakership in the south of Europe", Présidence(s) des institutions parlementaires et représentatives (XVe-XXe siècles) (Paris, 2021) y Mikel Urquijo, "The speakership of European parliaments in the contemporary age: the myth of "the servant of the house" or the partisan speaker", CISH's XXIII Congress (Poznan (Polonia), 2022). Asimismo hemos publicado: Mikel Urquijo, "Models of parliamentary speakership in the nineteenth and twentieth centuries: France, Italy, Portugal and Spain”, Parliaments, Estates \& Representation, n ${ }^{\circ}$ 40-3, 2020, pp. 308-323, Mikel Urquijo, "Parliamentary speakership: from individual speakership to the collective direction of parliamentary work”, Spanish Journal of Legislative Studies, $\mathrm{n}^{\circ}$ 2, 2020, artículo 3 y Mikel Urquijo, "La Presidencia del Parlamento en el marco de las revoluciones liberales del sur de Europa”, en Vital Moreira y José Domingues (coord.), Dois Séculos de Constitucionalismo Eleitoral (1820-2020): Atas da Conferência Internacional, Universidade Lusíada, Lisboa, 2021, pp. $317-$ 346.).

3 Miguel Ángel Giménez Martínez, Las Cortes españolas en el régimen de Franco. Nacimiento, desarrollo y extinción de una Cámara Orgánica, Congreso de los Diputados, Madrid, 2012, pp. 6672 .

4 José Manuel Tavares Castilho, “A Assembleia Nacional, 1934-1974: esboço de caracterização”, Penélope: revista de história e ciências sociais, $n^{\circ}$ 24, 2001, p. 65.

5 En el caso italiano hemos optado por analizar el parlamento desde 1924, año en que se renovó la cámara tras la modificación de la ley electoral (Legge Acerbo) que establecía una circunscripción electoral nacional y atribuía dos tercios de los escaños al partido que obtenía un $25 \%$ de los votos (portale storico de la Cámara (storia.camera.it). Agradezco la sugerencia de esta ampliación del periodo de análisis a nuestro colega Mario di Napoli. La periodización de la transformación de la Camera dei Deputati en Mario di Napoli, "Camera dei Deputati”, en Victoria de Grazia e Sergio Luzzato (a cura di), Dizionario del fascismo, Einaudi, Torino, 2002, vol. I, pp. 218221. 
que desempeñaron esta responsabilidad. Todo ello en contraste con el modelo de presidencia de los parlamentos democráticos posteriores en los citados países.

El estudio de la presidencia del Parlamento no ha sido un tema de especial interés para los historiadores. Resulta más habitual encontrar trabajos realizados desde la óptica del derecho o redactados por los letrados de las propias cámaras. Aunque esto no quiere decir que no existan trabajos históricos que nos permitan obtener una visión comparativa sobre el modelo de presidencia del Parlamento entre diferentes países. En el caso español podemos citar los trabajos de E. Jerónimo Sánchez-Beato ${ }^{6}$ que ofrecen un análisis de la normativa que regula la presidencia de las Cortes a lo largo de los siglos XIX y XX. En el caso italiano nos ha sido de utilidad la información contenida en la propia web del Parlamento (portale storico), los trabajos generales sobre la presidencia ${ }^{7}$ de S. Furlani y F. Mohrhoff y los más específicos sobre el periodo fascista de Enrico D'Alfonso y Francesco Bonini ${ }^{8}$. Por último, en Portugal no conocemos ningún trabajo específico sobre la presidencia de su parlamento, pero si hemos podido contar con la información de la propia web de la Asamblea.

Junto a estas obras sobre la presidencia de los países que analizamos también podemos contar con otros trabajos ${ }^{9}$ que nos pueden ofrecer referentes comparativos con Francia (Ph. Séguin e Y. Daudet), Reino Unido (Ph. Laundy M. Laban y P. Seaward), Estados Unidos (C. Albert, M.P. Follet, D. G. Hitchner, R.M. Peters y A.T. Zubrov) o la obra coordinada por J. Garrigues referida a los

6 Estefanía Jerónimo Sánchez-Beato y Miguel Ángel Morales Payán, La presidencia de las Cortes en el constitucionalismo histórico español, Universidad de Almería, Almería, 2004, Estefanía Jerónimo Sánchez-Beato y Miguel Ángel Morales Payán, De las Cortes Españolas al Congreso de los Diputados: el devenir de su presidencia (1942-78), Universidad de Almería, Almería, 2005 y Estefanía Jerónimo Sánchez-Beato, La Presidencia del Congreso de los Diputados en el sistema constitucional español de 1978, Ayuntamiento de Málaga, Málaga, 2006.

7 Silvio Furlani et alii, I Presidenti della Camera, Editalia, Roma, 1988 y Federico Mohrhoff, Introduzione ad uno studio sugli aspetti storico-politici, giuridico-costituzionali e regolamentariconsuetudinari dell'Istituto presidenziale del Parlamento italiano (1848-1963), Editore Colombo, Roma, s.d.

8 Enrico D'Alfonso, Ministro e Presidente della Camera dei fasci e delle corporazioni, Alberto Morano Ed., Napoli, 1940 y Francesco Bonini, "Présidents et bureaux de présidence de la Chambre italienne sous le fascisme (1922-1939)", en Parlamentos: a lei, a prática e as representaçoes. Da Idade Media à Actualidade / Parliaments: the Law, the practice and the representations. From the Middle Ages to the Present Day, Assembleia da República - Universidade de Coimbra, Lisboa, 2010, pp. 449-453.

${ }^{9}$ Pierre Séguin, 240 dans un fauteuil. La saga des présidents de l'Assemblée, Éditions du Seuil, Paris,1995, Yves Daudet, La Présidence des Assemblées parlementaires françaises, Presses Universitaires de France, Paris,1965, Philip Laundy, The Office of Speaker, Cassell \& Co. Ltd., London, 1964, Matthew William Laban, The Speaker of the House of Commons: The Office and Its Holders since 1945, PhD Thesis - University of London, London, 2014, Paul Seaward (ed.), Speakers and the Speakership. Presiding Officers and the Management of Business from the Middle Ages to the 21st Century, Parliamentary History, Oxford, 2010, Carl Albert, The office and the duties of the Speaker of the House of Representatives, Washington, U.S. Govt. Print. Off., 1976, Mary P. Follet, The Speaker of the House of Representatives, Longmans, Green and Co., New York, 1896, Dell G. Hitchner, "The Speaker of the House of Representatives", Parliamentary Affairs, XIII December, 1959, pp. 185-197, Ronald M. Peters Jr. (ed.), The speaker: leadership in the U.S. House of Representatives, Washington D.C, Congressional Quarterly, 1995, Alfred T. Zubrov (ed.), Speakers of the House 1789-2002, Hauppauge, NY, Novinka Books, 2002 y Jean Garrigues (dir.), Les Présidents de l'Assemblée nationale de 1789 à nos jours, Classiques Garnier, Paris, 2015. 
presidentes de la Asamblea Nacional francesa, en la que se recogen diferentes contribuciones analizando el caso francés y los de otros países europeos.

Además de estas obras generales sobre la presidencia del parlamento, en el caso español también contamos con un trabajo específico sobre las Cortes Españolas ${ }^{10}$, que dedica dos apartados a la Presidencia de la Cámara (pp. 164178), lo que nos facilita la contextualización del análisis de la presidencia en un estudio más amplio. Junto a esta obra, como referencia para el análisis de los reglamentos de estas asambleas y su significado nos remitimos al trabajo de Ignacio Fernández Sarasola ${ }^{11}$. En el caso italiano ${ }^{12}$ contamos con los trabajos de Stefano Sicardi, Francesco Perfetti, Eduardo Gianfrancesco y Mario di Napoli. En el caso portugués contamos con los trabajos de José Manuel Tavares Castilho, R. Almeida de Carvalho y Phillipe C. Schmitter para aproximarnos al estudio de la Asamblea del periodo de la dictadura ${ }^{13}$.

\section{LAS ASAMBLEAS DE LAS DICTADURAS}

En los tres países que analizamos se produjo una transformación del sistema político, pasando de un sistema democrático a una dictadura en la que el parlamento fue sustituido por una asamblea, en España e Italia de modelo corporativo, y en Portugal, manteniendo una ficción de sistema democrático. En los tres casos se formaron cámaras en las que no había cabida para una oposición real, bien porque una parte de los escaños estaban ocupados por personas nombradas directamente por el Gobierno o el mismo dictador o porque los procesos electorales desarrollados para elegir al resto de los representantes estaban controlados por el régimen para obtener los resultados adecuados ${ }^{14}$.

10 Miguel Ángel Giménez Martínez, Las Cortes españolas en el régimen de Franco. Nacimiento, desarrollo y extinción de una Cámara Orgánica, op. cit. No creemos necesario detallar los diferentes trabajos anteriores sobre las Cortes españolas, ya que se encuentran recogidos en esta obra.

11 Ignacio Fernández Sarasola, Reglamentos parlamentarios (1810-1977), Iustel, Madrid, 2012, pp. 90-105. También esta obra, en las páginas 115-116 se ofrece un comentario bibliográfico que complementa el anterior.

12 Stefano Sicardi, "Il fascismo in Parlamento: lo suuotamento della rappresentanza generale", en Luciano Violante (ed.), Storia d'Italia. Annali 17. Il Parlamento, Einaudi editore, Torino, 2001, pp. 253-290, especialmente 287-290, Francesco Perfetti, La Camera dei fasci e dei corporazioni, Bonacci Editore, Roma, 1991, Eduardo Gianfrancesco, "Parlamento e regolamenti parlamentari in epoca fascista", Osservatorio sulle fonti, $\mathrm{n}^{\circ}$ 2, 2008, pp. 1-32, Mario di Napoli, "Camera dei Deputati", op. cit., vol. I, pp. 218-221 y Mario di Napoli, "Camera dei fasci e delle corporazioni", en Victoria de Grazia e Sergio Luzzato (a cura di), Dizionario del fascismo, Einaudi, Torino, 2002, vol. I, pp. 221-224.

13 José Manuel Tavares Castilho, "A Assembleia Nacional, 1934-1974: esboço de caracterização", op. cit., pp. 65-84, José Manuel Tavares Castilho, A Assembleia Nacional (19341974), Tese submetida como requisito parcial para obtenção do grau de Doutor em História Moderna e Contemporânea, Lisboa, 2007, José Manuel Tavares Castilho, Os Deputados da Assembleia Nacional 1935-1974, Assembleia da República, Lisboa, 2009, Rita Almeida de Carvalho, A Assembleia Nacional no pos-guerra (1945-1949), Assembleia da República, Lisboa, 2002 y Phillipe C. Schmitter, Portugal: do Autoritarismo à Democracia, Instituto de Comunicação Social, Lisboa, 1999.

14 Un estudio reciente sobre los procesos electorales en España (para las elecciones municipales) y Portugal (para la Asamblea) en Carlos Domper Lasús, Dictatorship and the Electoral 
Aunque no vamos a entrar a analizar con detalle el papel de estas asambleas en las dictaduras citadas si consideramos necesario subrayar el cambio que introdujeron respecto a los parlamentos anteriores. Para ello analizamos las leyes ${ }^{15}$ que las regulaban y los reglamentos de las mismas ${ }^{16}$.

En el caso portugués, la Constitución de 1933 estableció la creación de una Asamblea Nacional ${ }^{17}$ y una Cámara corporativa ${ }^{18}$. La Asamblea Nacional se elegía por sufragio directo ${ }^{19}$. No era una cámara corporativa, como las de España e Italia. Esta Asamblea tenía capacidad legislativa, mientras la Cámara corporativa tenía como finalidad dar su parecer sobre las propuestas que se debatían en la Asamblea Nacional ${ }^{20}$. La Asamblea Nacional mantenía una formalidad similar a la de los parlamentos democráticos en muchos aspectos, aunque no pueda ser considerada como tal, dada la manera en que se elegía y la limitación de poderes a la que estaba sometida por el Ejecutivo ${ }^{21}$. En el periodo de la dictadura en Portugal todos los miembros de la Asamblea eran personas de confianza politica o miembros del partido único, União Nacional, por lo que la apariencia de pluralidad que podía dar el Reglamento de la Cámara se veía anulada por la fidelidad a la dictadura de todos los diputados ${ }^{22}$. En palabras de Schmitter: "um colégio de cardeais de carácter intelectual, administrativo e funcional, cujos membros haviam sido escolhidos por serviços prestados ao Estado"23.

En Italia el proceso fue diferente. La llegada del fascismo al poder no supuso el cierre del parlamento de la monarquía. La estrategia del fascismo fue

Vote. Francoism and the Portuguese New State Regime in Comparative Perspective. 1945-1975, Sussex Academic Press, Brighton-Chicago-Toronto, 2020.

15 En España la Ley de 17 de julio de 1942 de creación de las Cortes Españolas (en adelante LC1942) y la Ley de 17 de julio de 1942 de creación de las Cortes Españolas modificada por la disposición adicional tercera de la Ley Orgánica del Estado de 10 de enero de 1967 (en adelante MLC1967), en Italia la Legge 19 gennaio 1939. Istituzione della Camera dei Fasci e delle Corporazioni (en adelante LICFC1939) y en Portugal la Constituição Política da República Portuguesa de 1933 (en adelante CP1933).

16 En España son el Reglamento provisional de las Cortes españolas, 1943 (en adelante RE1943), el Reglamento de las Cortes españolas, 1957 (en adelante RE1957), el Reglamento de las Cortes españolas, 1967 (en adelante RE1967) y el Reglamento de las Cortes españolas, 1971 (en adelante RE1971), consultados en Ignacio Fernández Sarasola, Reglamentos parlamentarios (18101977), op. cit., pp. 378-458. En Italia el Regolamento del 31 ottobre 1925 (en adelante RI1925), Regolamento del 12 dicembre 1930 (en adelante RI1930) y Regolamento del 14 dicembre 1938 (en adelante RI1938), consultados en el portale storico de la Camera dei Deputati (storia.camera.it). Y en Portugal el Regimento provisório da Assembleia Nacional, 1935 (en adelante RP1935) y el Regimento da Assembleia Nacional, 1973 (en adelante RP1973), consultados en la página web de la Assembleia da República (www.parlamento.pt).

17 Artículos 85 a 101 de la CP.

18 Artículos 102 a 106 de la CP.

19 Sobre los cambios constitucionales que regulan la Asamblea de Portugal, ver José Manuel Tavares Castilho, A Assembleia Nacional (1934-1974), op. cit., pp. 124-138.

20 Artículo 103 de la CP.

${ }^{21}$ Ver José Manuel Tavares Castilho, A Assembleia Nacional (1934-1974), op. cit., pp. 124-138.

22 José Manuel Tavares Castilho, A Assembleia Nacional (1934-1974), op. cit., pp. 228-275.

${ }^{23}$ Phillipe C. Schmitter, Portugal: do Autoritarismo à Democracia, op. cit., p. 36. 
transformarlo progresivamente ${ }^{24}$. De esta manera, se desarrolló un proceso de "deconstrucción" del parlamento, que progresivamente fue modificándolo, a través de la limitación de los derechos de los diputados, de cambios en la legislación electoral y de los procedimientos de la vida parlamentaria ${ }^{25}$. Finalmente, en 1939 se aprobó la sustitución de la Camera dei Deputati por la Camera dei fasci e delle corporazioni, formada por personas designadas por el Gobierno, que abandonó "todo simulacro de representación político-electoral" 26 y en la que no había cabida para el debate ni para ninguna forma de oposición al fascismo. Al mismo tiempo se mantuvo el Senado ${ }^{27}$, aunque el gobierno de Mussolini lo fue transformando con el nombramiento de nuevos senadores fascistas. El Duce asumió facultades para intervenir en las labores de la Cámara, como la elaboración del orden del día o la decisión sobre la sanción regia a las leyes aprobadas. El parlamento perdía su autonomía frente al ejecutivo y desarrollaba su labor bajo el control del gobierno ${ }^{28}$. El concepto de división de poderes fue sustituido por el concepto fascista de un poder unitario con una diversidad de funciones ${ }^{29}$. Con lo que la Cámara quedaba supeditada al control del Ejecutivo.

En España, tras la victoria de los sublevados en la Guerra Civil (1936-1939) la Dictadura clausuró el parlamento e inició un proceso de institucionalización del régimen basado en las Leyes Fundamentales ${ }^{30}$ y la participación de la población en la vida politica a través de la representación corporativa, basada en la familia, el municipio y el sindicato único, configurando lo que denominaba como democracia orgánica ${ }^{31}$, en la que no había lugar para los partidos políticos salvo el partido único. En este modelo de estado se enmarca la creación de una asamblea corporativa con la denominación de Cortes Españolas ${ }^{32}$ con la misión

${ }^{24} \mathrm{El}$ proceso de transformación de la Cámara en tres fases en Mario di Napoli, "Camera dei Deputati”, op. cit., vol. I, pp. 218-221.

25 Eduardo Gianfrancesco, "Parlamento e regolamenti parlamentari in epoca fascista", op. cit., pp. 1-32, Stefano Sicardi, "Il fascismo in Parlamento: lo svuotamento della rappresentanza generale", op. cit., pp. 278-286 y Giampiero Buonomo, "La decadenza dei Deputati nella Camera del Regno d'Italia del 9 novembre 1926", Historia constitucional, nº 13, 2012, pp. 697-715.

26 Stefano Sicardi, "Il fascismo in Parlamento: lo suuotamento della rappresentanza generale", op. cit., p. 287.

27 Mario di Napoli, "Senato del Regno", en Victoria de Grazia e Sergio Luzzato (a cura di), Dizionario del fascismo, Einaudi, Torino, 2003, vol. II, pp. 618-621.

28 Federico Mohrhoff, Introduzione ad uno studio sugli aspetti storico-politici, giuridicocostituzionali e regolamentari-consuetudinari dell'Istituto presidenziale del Parlamento italiano (18481963), op. cit., pp. 69-70. 6.

${ }^{29}$ Enrico D’Alfonso, Ministro e Presidente della Camera dei fasci e delle corporazioni, op. cit., p.

30 Término apreciado por el tradicionalismo. Estas leyes fueron aprobadas por diferentes procedimientos en los que participó el Jefe del Estado, las Cortes Españolas o fueron sometidas a referéndum. Joaquín Varela Suanzes-Carpegna, Constituciones y leyes fundamentales, Iustel, Madrid, 2012, pp. 117-118.

31 Joaquín Varela Suanzes-Carpegna, Constituciones y leyes fundamentales, op. cit., pp. 124125.

32 En esta denominación se utiliza el termino tradicional de Cortes, que se modifica cambiando el término generales por el de españolas, para evidenciar, también en la denominación, la ruptura con el modelo de parlamentarismo liberal. 
de "reanudar gloriosas tradiciones españolas"33. Esta asamblea fue concebida como el órgano de participación del pueblo con la función de facilitar el "contraste de pareceres" y preparar las leyes que aprobaría Franco. Al igual que en la asamblea italiana sus miembros eran designados, inicialmente. En las reformas posteriores se introdujeron miembros elegidos, pero en un proceso controlado por las autoridades de la Dictadura que limitaba extraordinariamente la representación de los procuradores ${ }^{34}$.

En definitiva, se crearon unas asambleas que no representaban a los ciudadanos, sino a las corporaciones y en último caso a los miembros del partido único, en procesos de elección controlados. Todo ello contrasta extraordinariamente con el modelo de parlamento anterior y posterior, en el que los diputados eran elegidos por sufragio universal, inicialmente masculino y posteriormente incluyendo a las mujeres. Se modificaba la idea de representación y se presentaba una "representación más real" que correspondía a los "intereses de todas las fuerzas vivas y vitales de la nación"35. A su vez la idea de la división de poderes fue sustituida por la del poder único y la división de funciones, con la que la Cámara quedaba supeditada al Gobierno, que concentraba el poder. Por supuesto, esto conllevaba que la función de control al Gobierno que ejercía el Parlamento en los sistemas liberales y democráticos desapareció.

Este cambio del modelo de asamblea y el control que ejercía el Ejecutivo sobre la Asamblea se evidenciaban en la pérdida de la capacidad de autorregulación del propio Parlamento. Desde las primeras experiencias de parlamentarismo liberal ${ }^{36}$ en España, Italia y Portugal las cámaras habian elaborado sus reglamentos y esta prerrogativa parlamentaria fue reconocida en sus constituciones ${ }^{37}$. Esta capacidad de autorregulación del parlamento, que se plasmaba en la elaboración del propio reglamento es común a todos los parlamentos de Europa occidental en el siglo XX y es una garantía de la autonomía del Parlamento ${ }^{38}$. Frente a ello las asambleas de las dictaduras limitaron esta prerrogativa parlamentaria.

En Italia la Cámara mantuvo la capacidad de autorregulación en el periodo fascista. Entre 1924 y 1938, se mantuvo formalmente la vigencia de la legislación liberal, aunque se avanzó en el proceso de "deconstrucción" del parlamento al que nos referiamos antes. A partir de 1939 la Cámara corporativa mantuvo la capacidad de elaborar el reglamento, pero al mismo tiempo durante este periodo de transformación del parlamento se aprobaron diferentes leyes que minaron esta

33 Exposición de motivos de la LC1942.

34 Miguel Ángel Giménez Martínez, Las Cortes españolas en el régimen de Franco. Nacimiento, desarrollo y extinción de una Cámara Orgánica, op. cit., p. 345. 5 .

35 Enrico D’Alfonso, Ministro e Presidente della Camera dei fasci e delle corporazioni, op. cit., p.

36 Josu de Miguel Barcena, "El reglamento parlamentario en los origenes del constitucionalismo europeo y español”, Historia constitucional, n 17, 2016, pp. 55-81.

37 En España en la Constitución de 1812 (art. 127), en Portugal en la Constitución de 1822 (art. 103.16) y en Italia en el Estatuto Albertino de 1848 (art. 61).

38 Juan Cano Bueso, "El principio de autonormatividad de las cámaras y la naturaleza jurídica del reglamento parlamentario", Revista de Estudios Políticos, n 40, 1984, pp. 85-99, especialmente pp. 89-90. 
capacidad, como las que establecían que el orden del día de la Cámara era establecido por el Duce ${ }^{39}$, la capacidad del Duce de aprobar el inicio de las iniciativas legislativas propuestas por los consejeros (art. 61 del Reglamento) o la participación del Duce en el proceso legislativo. Todo ello, en la práctica, limitaba la autonomía parlamentaria.

En España la Ley de Cortes de 1942 preveía que el Reglamento de las mismas fuese elaborado por la Asamblea de acuerdo con el Gobierno ${ }^{40}$. Por tanto, se volvía a la intervención gubernamental en detrimento de la capacidad de autorregulación del Parlamento, que había sido la norma en la mayoría de los periodos constitucionales anteriores. El primer reglamento de las Cortes Españolas fue obra del Gobierno (Ley de 5 de enero de 1943), que aunque provisional tuvo una permanencia de 15 años. A partir de este momento las sucesivas reformas del Reglamento (1946, 1957, 1967 y 1971) fueron realizadas por las Cortes de acuerdo con el Gobierno.

En Portugal la Asamblea Nacional mantuvo la capacidad de autorregulación ${ }^{41}$ frente a lo que sucedia en España e Italia.

Por tanto, podemos concluir que en España e Italia se limitó la capacidad de autorregulación de la asamblea, incrementando los poderes del Gobierno, mientras en Portugal se mantuvo un sistema formalmente similar al de los parlamentos liberales.

\section{LA REgULACIÓN DE LA PRESIDENCIA DE LAS ASAMBLEAS DE LAS DICTADURAS}

Una segunda cuestión que contrasta con la regulación de los parlamentos liberales anteriores es el sistema de elección del presidente de la cámara. Salvo en los parlamentos que seguian el modelo de la Asamblea francesa de 1814, la elección del presidente de la cámara baja por los propios diputados en España ${ }^{42}$, Portugal $^{43}$ e Italia $^{44}$ ha sido una constante desde el inicio del parlamentarismo

39 Eduardo Gianfrancesco, "Parlamento e regolamenti parlamentari in epoca fascista", op. cit., pp. 1-32 y especialmente 19-21.

40 Disposición adicional primera de la LC1942.

41 Artículo 86 de la CP.

42 La Constitución de Cádiz de 1810 lo estableció en el artículo 118. Se repitió la fórmula en la Constitución de 1837 (art. 30), en la Constitución de 1845 (art. 29), en la Constitución de 1869 (art. 45) y en la Constitución de 1876 (art. 35). En la Constitución de 1931 no se hizo referencia a la elección del presidente del parlamento, pero en el artículo 57 se establecía la capacidad del parlamento de regular su funcionamiento interno y por tanto de aprobar su reglamento, en el que se confería a la cámara la potestad de la elección de su presidente (Reglamento del Congreso de los Diputados de 1934, art. 4 a 6 y 24).

43 La Constitución de 1822 lo estableció en el artículo 78. Se repitió la fórmula en la Constitución de 1838 (art. 43) y en la Constitución de 1911 (art. 13).

44 El Estatuto Albertino de 1848 lo estableció en el artículo 43. 
liberal. F. Mohrhoff lo define como uno de las más sagradas e inviolables garantías constitucionales de la Asamblea ${ }^{45}$.

En las asambleas de las dictaduras también esto cambió en España e Italia.

En Italia en el periodo anterior a la creación de la cámara corporativa el parlamento mantenía la capacidad de nombrar a su presidente. En el periodo de "deconstrucción" del parlamento por el fascismo se mantuvo esta prerrogativa parlamentaria. En los reglamentos de 1925 y 1930 los diputados eran quienes elegian al Presidente ${ }^{46}$. A partir de 1939, el Presidente y los vicepresidentes de la Cámara eran nombrados por un real decreto de acuerdo con la Ley que creó la Cámara corporativa ${ }^{47}$. El Presidente asumia sus funciones diez días antes del inicio de la legislatura (art. 1 del RI1938), es decir, que su nombramiento se hacia totalmente al margen de la Cámara. La duración de su mandato era indefinida. La falta de independencia de esta Cámara frente al Gobierno resultaba muy evidente. Una muestra de ello fue el nombramiento como presidente de Dino Grandi, que a la vez mantenía su cargo de Ministro de Justicia ${ }^{48}$. Como comentábamos anteriormente el principio de separación de poderes era ignorado completamente.

En España entre 1942 y 1967 la Mesa de las Cortes era nombrada por Franco. A partir de este año el Presidente era nombrado por el Jefe del Estado, entre los procuradores que figurasen en una terna presentada por el Consejo del Reino, y los Vicepresidentes y Secretarios elegidos por la Asamblea ${ }^{49}$.

El proceso de nombramiento marcaba una importante diferencia con los parlamentos liberales y democráticos. Definía un modelo de presidencia en el que el Presidente era independiente de la Cámara y desempeñaba la función de enlace entre la Cámara y el dictador ${ }^{50}$.

En el caso español, también desde el punto de vista simbólico se establecía otra diferencia. E1 Presidente de las Cortes Españolas juraba su cargo ante el Jefe del Estado51, frente a la tradición parlamentaria española que establecía que el Presidente lo hacía en la Cámara ante el Presidente de la Mesa interina. Este procedimiento de juramento mostraba, también formalmente, que el presidente no era el elegido de los elegidos ${ }^{52}$, sino que era el representante del Gobierno para controlar a las Cortes.

45 Federico Mohrhoff, Introduzione ad uno studio sugli aspetti storico-politici, giuridicocostituzionali e regolamentari-consuetudinari dell'Istituto presidenziale del Parlamento italiano (18481963), op. cit., p. 36.

46 Artículo 4 del RI1925 y artículo 4 del RI1930.

47 Artículo 11 de la LICFC1939.

48 Se ofrece una justificación de este modelo por la idea fascista de representación y de poder único en Enrico D’Alfonso, Ministro e Presidente della Camera dei fasci e delle corporazioni, op. cit.

49 Artículo séptimo de la LC1942 y artículo séptimo, apartado I y artículo séptimo, apartado V de la MLC1967.

50 Enrico D'Alfonso, Ministro e Presidente della Camera dei fasci e delle corporazioni, op. cit., pp. $10-11$.

51 Artículo 10 del RE1943, artículo 13 del RE1957, artículo 13 del RE1967 y artículo 16 del RE1971.

52 Silvio Furlani et alii, I Presidenti della Camera, op. cit., p. 9. 
Otra diferencia relevante, en el caso español, residía en la duración del mandato. Hasta 1967 no se establecía en el reglamento, por lo que dependía de la voluntad de Franco o de la salud de los nombrados. Esteban Bilbao Eguia, primer presidente de las Cortes Españolas ocupó este cargo durante 22 años ${ }^{53}$, hasta los 86 años, en un total de 7 legislaturas. Esta permanencia en el cargo era otro de los elementos que caracterizaba este modelo de presidencia ligado a la voluntad del dictador y sin ninguna relación con los procesos de elección de la asamblea. Tras la prolongada presidencia de Esteban Bilbao, en 1967 se reformó el reglamento de las Cortes y se estableció la duración del mandato en seis años. Un periodo que no coincidía con la renovación de la cámara y por tanto, un elemento más, de la configuración de un modelo de presidencia ligado a la voluntad de Franco. Por otra parte, el nuevo reglamento no estableció ninguna previsión sobre la repetición de mandatos, aunque nunca se produjeron a partir de este momento.

En Portugal el Presidente, los vicepresidentes y los secretarios eran elegidos por la Cámara54. El Presidente era elegido para toda la legislatura y los vicepresidentes para el periodo de sesiones. Debemos destacar que aunque en esta cámara se mantuviesen bastantes elementos formales del parlamentarismo liberal, en el caso de la Mesa encontramos una diferencia relevante. Este órgano estaba compuesto por el Presidente y los dos secretarios. Los vicepresidentes solo participaban cuando sustituían al Presidente, pero si no, no lo hacían. Es decir, que la Presidencia también tenía un carácter unipersonal como en el caso español e italiano, en contraposición al modelo anterior y especialmente al posterior a las dictaduras.

En el proceso de elección del presidente también observamos un gran paralelismo entre los casos español e italiano y una mayor distancia con Portugal. Aunque si existe un elemento común. Se definía una presidencia unipersonal en la que el que la ocupaba era el verdadero jefe mas que un "primus inter pares"55. Las funciones de la mesa que se definirán con mayor claridad a partir de mediados del siglo XX son desempeñadas en buena medida por el Presidente, emulando en cierto modo el modelo de presidencia del Speaker británico, en la que no cuenta con una mesa con la que compartir su responsabilidad.

Otro de las cuestiones que vamos a examinar con detalle, para conocer el modelo de presidencia, es la atribución de las funciones que realizaba el reglamento. Los presidentes de las asambleas que estamos examinando desempeñaban las funciones habituales en los parlamentos liberales: la dirección de los trabajos parlamentarios, el mantenimiento del orden en la Cámara, la participación en la administración parlamentaria y la representación de la Cámara, a las que añadian otras que reforzaban su poder en comparación con el modelo de presidencia del parlamento liberal anterior.

53 El mandato se prolongó desde el 16 de marzo de 1943 al 29 de septiembre de 1965.

54 Artículo 86 de la CP y artículo 3 del Reglamento de 1935 y artículo 8 del RP1973.

55 Miguel Ángel Giménez Martínez, Las Cortes españolas en el régimen de Franco. Nacimiento, desarrollo y extinción de una Cámara Orgánica, op. cit., pp. 164-165. 
En relación con la dirección de los trabajos parlamentarios el Presidente convocaba el Pleno, salvo en Italia a partir de 193956, abría y cerraba las sesiones, dirigía los debates y las votaciones, organizaba el trabajo de la asamblea y hacía cumplir el reglamento57. Estas son las funciones que competen a la presidencia en la mayoria de los reglamentos parlamentarios de España, Italia y Portugal en el periodo anterior y en el posterior al que analizamos.

La peculiaridad de estas asambleas es que la Presidencia veía reforzadas sus funciones en mayor o menor media en este ámbito. En el caso portugués el Presidente establecía el orden del día de las sesiones, podía decidir que la sesión fuese secreta, juzgaba las justificaciones de las faltas de los diputados (esto es interesante porque le confería una capacidad importante de control sobre los diputados), tenía cierta capacidad para crear comisiones y nombrar alguna de ellas $^{58}$ y en 1973 se le confirió la potestad de interpretar el reglamento ${ }^{59}$.

En Italia60 se produjo una evolución desde los reglamento de 1925 y 1930 al de 1938, en la que se fueron incrementando los poderes de la presidencia. En 1925 las únicas funciones que destacaban frente a otros países era su capacidad para verificar el quorum y el nombramiento de los miembros de la Giunta permanente per il Regolamento interno, la Giunta delle elezioni y la Commissione per l'esame delle domande di autorizzazione a procedere. Pero en realidad no suponian un reforzamiento de la presidencia porque ya eran funciones que estaban recogidas en el reglamento de 1900. En 1930 el cambio más reseñable en este apartado fue que el orden del día no lo establecía ni el Presidente, ni la Cámara, sino que lo establecía el Gobierno ${ }^{61}$. También el Presidente asumía la capacidad de declarar secreta la sesión y mantenía la de verificar el quorum. En 1938 se produjeron cambios más importantes. En primer lugar, el Duce convocaba las sesiones y establecía el orden del día. El Presidente podía crear comisiones, nombrar los miembros de las comisiones, sus presidentes y secretarios y podía presidir cualquiera de ellas y nombrar los secretarios y cuestores de la cámara.

España, es sin duda, el caso en el que más se reforzaron las funciones de la presidencia $^{62}$. El Presidente de las Cortes convocaba el pleno de constitución,

56 En este Reglamento se recogía que quien convocaba la Cámara era el Duce, artículos 4 y 15 de RI1938.

57 En el caso español estaba recogido en los artículos 11, 34, 35, 38 y 53 del RE1943, los artículos 14, 34, 39 y 67 del RE1957 y los artículos 18 y 56 a 61 del RE1971. En el caso italiano en los artículos 11, 14 y 31 del RI1925, en los artículos 11, 13 y 21 del RI 1930 y en los artículos 6 y 15 y los capítulos 6 y 8 del RI1938. En el caso portugués en el artículo 23 y el capítulo 3 del RP1935 y en los artículos 11 y 42 del RP1973.

58 Nombraba la comisión que se encargaba de dar la redacción definitiva a los proyectos aprobados (debía escoger a sus componentes entre los diputados que fuesen especialistas en derecho).

${ }^{59}$ Artículos 16, 23 y 29 de RP1935 y artículos 20 y 42 del RP1973.

60 Artículos 12 y 35 del RI1925. Artículos 26 y 76 del RI1930. Artículos 4, 6, 15, 18 y 32 del RI1938

61 Artículo 6 de la Legge 24 dicembre 1925. Attribuzioni e prerogative del Capo del Governo, Primo Ministro Segretario di Stato.

62 Artículos 4, 6, 8, 11, 16, 19 y 57 del RE1943. Artículos 3, 7, 14, 16, 19, 22, 25, 75 y 77 del RE1957. Artículos 5, 9, 18, 26 y 125 del RE1971. 
podía interpretar el reglamento y declarar sesión secreta, modificar los plazos de tramitación de los proyectos, crear comisiones y nombrar a sus miembros, de acuerdo con el Gobierno en 1943 y también con la Comisión Permanente, a partir de 1957, nombrar los presidentes, presidir cualquier comisión, limitar las interpelaciones al Gobierno (únicamente en el Reglamento de 1957), despachar los asuntos urgentes, en las vacaciones parlamentarias, junto con la Comisión Permanente y establecer el orden del dia, de acuerdo con el Gobierno. A ello añadía su capacidad para autorizar la detención de un procurador y, de acuerdo con la Comisión Permanente, aprobar su procesamiento.

En los tres países vemos un reforzamiento del poder de la presidencia para controlar el trabajo parlamentario, en detrimento del Pleno o de la Mesa de la Cámara, lo que distancia a estas asambleas de los parlamentos democráticos ${ }^{63}$. Aunque este cambio fue desigual, mayor en España que en Italia y en ambos casos mayor que en Portugal. En el caso italiano vemos un importante reforzamiento del control directo del Gobierno sobre la Cámara a través de la capacidad de convocatoria del pleno y de establecimiento del orden del día. Obviamente la función de control al gobierno se vio enormemente limitada con su participación en algunas de las funciones a las que nos hemos referido.

En segundo lugar, nos referiremos a las funciones disciplinarias. Entre estas encontramos las habituales en la historia parlamentaria de estos países, pero en algunos casos con modificaciones sobre lo que suele ser habitual. En todos los reglamentos, a excepción del español de 194364, el Presidente desempeñaba la función de llamar al orden y a la cuestión a los oradores, la de retirar el uso de la palabra si no atendian sus avisos, la de mantener el orden y la autoridad sobre las fuerzas de orden público que custodiaban el palacio65. Estas funciones son las habituales en los reglamentos parlamentarios anteriores y posteriores a este periodo.

Pero como indicábamos en el apartado anterior, también en el ámbito disciplinario encontramos algunas funciones que no estaban reguladas de la misma manera en todos los reglamentos analizados 66 . En primer lugar, encontramos la capacidad del presidente de expulsar de la sala a un diputado o suspenderlo en sus funciones cuando ignorase las llamadas al orden. En España el presidente sólo podía expulsarlo, en Portugal podía hacer ambas cosas y en

63 "The free mandate for deliberation distinguishes a parliament from assemblies representing estates, soviets and corporative bodies", Kari Palonen, "Thinking of Politics in a Parliamentary Manner. Perspectives on the Conceptual History of Parliamentarism", en Pasi Ihalainen, Cornelia Ilie, Kari Palonen (eds.), Parliament and Parliamentarism. A comparative History of a European Concept, Berghahn, New York - Oxford, 2016, p. 229.

${ }^{64}$ Este reglamento era más breve que los que le sucedieron y detallaba en menor medida las funciones de la Presidencia. En su artículo 11 recogía una función genérica de mantener el orden, pero sin mayores detalles.

65 En España en el artículo 11 del RE1943, en los artículos 14 y 67 del RE1957 y en los artículos 18 y 54 del RE1971. En Italia en los artículos 14, 40, 43 y 69 del RI1925, en los artículos 13, 31, 32, 34 y 60 del RI1930 y en los artículos 6, 19 y 21 del RI1938. En Portugal en los artículos 4 y 23 del RP1935 y en los artículos 6 y 42 del RP1973.

66 En el artículo 11 del RE1943, en los artículos 14, 67 y 77 del RE1957 y en los artículos 54 y 127 del RE1971. En los artículos 41, 42 y 47 del RI1925, en los artículos 32 y 33 del RI1930 y en los artículos 6, 19, 20 y 23 del RI1938. En el artículo 4 del RP1935 y en el artículo 6 del RP1973. 
Italia también, pero sometiéndolo a la aprobación del Pleno de la Cámara. En segundo lugar, estaba la posibilidad de suspender las sesiones. En Italia, lo podía hacer, en España, lo podía hacer con el acuerdo del Gobierno, aunque no en el reglamento de 1971, y en Portugal no se recogía esta función en los reglamentos analizados. En tercer lugar, estaba la autoridad para expulsar al público de las tribunas en caso de alteración del orden, que se recogía en España e Italia, pero no en Portugal. Por último, en el caso italiano el Presidente podía aprobar sanciones para los miembros de la Cámara, con el acuerdo de la Mesa.

En relación con las funciones disciplinarias no se puede destacar un especial reforzamiento de las mismas respecto a otros reglamentos. Se puede destacar que en muchos de los reglamentos se suele contar con el acuerdo del Pleno o de la Mesa de la Cámara para aprobar las sanciones más graves, como la suspensión de las funciones de un diputado, pero al margen de esto no se concedía una gran autoridad al Presidente sobre el resto de componentes de la Cámara.

En tercer lugar, nos referiremos a la dirección de la administración parlamentaria. Desde los primeros pasos del parlamentarismo liberal esta función la ha desempeñado la presidencia en el seno de un órgano colectivo, como la comisión de gobierno interior o la mesa de la cámara67.

En este periodo, en las Cortes Españolas el Presidente desempeñaba estas funciones en el seno de la Comisión de Gobierno Interior, en los reglamentos de 1943, 1957 y 1967, y en el de la Mesa en el de 1971. En el caso italiano, en el seno de la Mesa, con la colaboración de los cuestores. Y en el caso portugués de manera individual. En este caso los reglamentos eran menos detallados que en los otros dos países ${ }^{68}$.

Por último, la función de representación seguía siendo relevante en la Presidencia de las asambleas analizadas ${ }^{69}$. Los presidentes ejercían la representación de las mismas ante otros órganos o instituciones, comunicaban a otras instituciones las resoluciones de las cámaras, solicitaban la información necesaria para el desarrollo de su labor, invitaban a participar a quien fuese necesario para el desarrollo del trabajo parlamentario y recibian las comunicaciones dirigidas a la Cámara.

Como hemos detallado en los párrafos anteriores los presidentes de las asambleas de las tres dictaduras desempeñaban las funciones habituales en los parlamentos de estos países, anteriores a las dictaduras. A ellas sumaban otras,

67 En España el Reglamento para el gobierno interior de las Cortes de 1813 dedicaba su capitulo XVIII a regular la Comisión de Gobierno interior y en Portugal el Regimento para o governo interior das Cortes Geraes, e extraordinarias constituintes, 1821 se refiere en su Título XI a la Junta da Inspecção.

68 En el artículo 20 y en la disposición adicional primera del RE1943, en el artículo 23 y en la disposición adicional primera del RE1957 y en el artículo 19 y en la disposición adicional primera del RE1971. En los artículos 17 y 147 del RI1925, en los artículos 16 y 134 del RI1930 y en el artículo 6 del RI1938. En el artículo 4 del RP1935 y en el artículo 6 del RP1973.

69 En los artículos 5, 11 y 13 del RE1943, en los artículos 14 y 16 del RE1957 y en los artículos 17 y 18 del RE1971. En los artículos 14 y 51 del RI1925, en los artículos 13 y 42 del RI1930 y en los artículos 1, 5, 6 y 17 del RI1938. En el artículo 23 del RP1935 y en los artículos 5, 11 y 42 del RP1973. 
especialmente en la dirección de los trabajos parlamentarios, que permitían un mayor control de la actividad de la cámara por su presidente, y en consecuencia por el gobierno que lo nombraba, salvo en Portugal. Y por otra parte, limitaba extraordinariamente la capacidad de control al Gobierno, de acuerdo con la supresión del principio de la separación de poderes.

A este incremento del poder de la presidencia, en el caso español ${ }^{70}$, se añadía su papel en otros órganos del estado, ya que era el Presidente del Consejo de Regencia y del Consejo del Reino, de acuerdo con lo establecido en la Ley de Sucesión de la Jefatura del Estado de 26 de julio de 194771, lo que incrementaba su relevancia en el entramado institucional de la dictadura.

Por último, no debemos olvidar que junto a estas funciones, lo que confería una extraordinaria autoridad a estos presidentes era la confianza politica de los tres dictadores, bien porque los nombraban directamente como en España e Italia o porque en algunos casos eran personas próximas al dictador como en Portugal.

La primera conclusión que extraemos de este análisis de las funciones de la presidencia es que contaba con un mayor poder que el que tenia la presidencia en el periodo anterior y posterior. Por otra parte, en el caso italiano y español su nombramiento por el dictador, en España, Jefe del Estado, y en Italia, a través de un Decreto Real, reforzaban esta figura. En el caso portugués, podemos considerar que esta figura no resultaba tan fuerte. Sus poderes no resultaban tan extraordinarios como en los otros dos casos, aunque eran superiores a los de las cámaras democráticas. Por otra parte, su nombramiento correspondía a la Cámara, aunque la relación personal de los presidentes con el dictador, en algunas de las figuras analizadas como el caso de José Alberto dos Reis ${ }^{72}$, también nos permite afirmar que su autoridad era mayor que la que se podría pensar en apariencia.

Estas funciones reforzadas, especialmente en España e Italia, concordaban con el concepto de un único poder con diversidad de funciones. El dictador nombraba a una persona de su confianza para presidir la asamblea y controlarla, al margen de los componentes de la misma.

Frente a estas afirmaciones se podría argumentar que existen otros modelos con unas relevantes funciones por parte del presidente del parlamento. Por ejemplo, en el caso británico también encontramos que el Speaker tiene unas funciones más importantes en la dirección de los trabajos parlamentarios ${ }^{73}$ que las de los presidentes de las cámaras de la Europa continental. Pero una diferencia fundamental entre el Speaker y los presidentes de las asambleas de las dictaduras estriba en que este es elegido por la Cámara y representa su opinión frente a los otros poderes del Estado, en lo que se suele denominar como the first

70 Ignacio Fernández Sarasola, Reglamentos parlamentarios (1810-1977), op. cit., pp. 100-101.

71 Artículo cuarto de la Ley de sucesión en la Jefatura del Estado de 26 de julio de 1947 (BOE, 27 de julio de 1947).

72 Manuel Braga da Cruz e António Costa Pinto, Dicionário biográfico parlamentar (1935-1974), Assembleia da República, Lisboa, 2005, vol. II, pp. 445-447.

73 Un ejemplo sería su capacidad para decidir que enmiendas se someten a votación, ver Standing Orders of the House of Commons - Public Business 2017, $\mathrm{n}^{\circ}$ 32. Selection of amendments, approved in 1919. 
Commoner $^{74}$, lo que sin duda le confiere una gran legitimidad democrática, mientras los otros deben su cargo a la voluntad del dictador sin ninguna otra legitimación.

\section{LOS PRESIDENTES DE LAS ASAMBLEAS DE LAS DICTADURAS}

A continuación analizaremos quiénes fueron los presidentes de estas asambleas, utilizando la prosopografia como método ${ }^{75}$. Para ello hemos obtenido la información biográfica necesaria de los personajes españoles del Diccionario Biográfico Español76, del Diccionario biográfico de los parlamentarios de Vasconia (1876-1939) ${ }^{77}$ y la página web del Congreso de los Diputados ${ }^{78}$, de los personajes italianos de las obras de S. Furlani y F. Bonini ${ }^{79}$, del Dizionario biografico degli italiani $^{80}$ y del portal histórico de la Camera dei Deputati ${ }^{81}$ y de los personajes portugueses del Dicionário biográfico parlamentar ${ }^{82}$ y de la página web de la Assembleia da República ${ }^{83}$.

En este análisis vamos a contrastar los datos del periodo de las asambleas de las dictaduras (España (1943-1977), Italia (1924-1943) y Portugal (1935-1974) con el de los parlamentos democráticos que les sucedieron. Pero en este último caso, vamos a utilizar como elemento comparativo un periodo de aproximadamente una década tras la caída de las dictaduras (España (19771987), Italia (1946-1958) y Portugal (1975-1987). La razón de la concreción de este periodo es que si tomamos todo el periodo hasta la actualidad distorsionaremos la comparación, dado que los cambios sociales en estos países a lo largo de tantos años pueden haber influido en una modificación de la caracterización social de los presidentes de las cámaras.

74 Philip Laundy, The Office of Speaker, op. cit., p. 250.

75 Algunas referencias que nos han servido para definir el modelo de estudio son: Lawrence Stone, El pasado y el presente, FCE, Mexico, 1986, Claude Sotinel, "Prosopographie et biographie", en Problemes \& Methodes de la biographie. Actes du Colloque (Sorbonne, 3-4 mai 1985), Paris, 1985, pp. 149-151, Neithard Bulst, "Prosopography and the Computer: Problems and Possibilities", History and Computing, vol. II, 1989, pp. 13-18, Toine Schijvenaars, "Computerized Prosopographical Research", en Koen Goudriaan, Kees Mandemakers, Jogchum Reitsma, Peter Stabel (eds.) Prosopography and Computer. Contributions of Mediaevalists and Modernists on the Use of Computer in Historical Research, Leuven, 1995, p. 1-24 y Katharine S.B. Keats-Rohan, "Prosopography and Computing: a Marriage made in Heaven?", History and Computing, vol. 12-1, 2000, pp. 1-11.

76 Diccionario Biográfico Español (http://dbe.rah.es/).

77 Diccionario biográfico de los parlamentarios de Vasconia (1876-1939), Parlamento Vasco, Vitoria-Gasteiz, 2007, 3 vols. La biografia de Esteban Bilbao en el vol. I, pp. 694-704.

78 Congreso de los Diputados: www.congreso.es.

79 Silvio Furlani et alii, I Presidenti della Camera, op. cit. Francesco Bonini, "Présidents et bureaux de présidence de la Chambre italienne sous le fascisme (1922-1939)", op. cit.

80 DIZIONARIO biografico degli italiani. http://www.treccani.it/biografico.

${ }^{81}$ Camera dei Deputati: Portale storico: storia.camera.it.

82 Manuel Braga da Cruz e António Costa Pinto, Dicionário biográfico parlamentar (1935-1974), op. cit.

${ }^{83}$ Assembleia da República: https://www.parlamento.pt/. 
Los indicadores que utilizaremos en este análisis serán su edad al acceder al cargo, su origen geográfico y familiar, su formación y profesión y su carrera politica previa y posterior al desempeño de la presidencia.

La edad a la que estas personas llegaban a la presidencia, en el periodo de las dictaduras, estaba situada entre los 54 y 64 años. Si tenemos en cuenta que la esperanza media de vida al nacer en Europa en 1950 era de 64'7 años y en 1973 de 70'9 años ${ }^{84}$ podemos afirmar que eran personas en la madurez. Aunque debemos destacar que en este grupo probablemente la esperanza media de vida era mayor que en la media del país. Si tomamos la edad de los más jóvenes, vemos que en España ${ }^{85}$ y Portugal ${ }^{86}$ superaban los 50 y únicamente en el caso de Italia, Dino Grandi era una persona de menor edad (44 años). Es decir, que la edad avanzada concuerda con personas con una relevante experiencia politica previa.

\section{Tabla 1. Media de edad de los presidentes \\ de las Asambleas al acceder al cargo}

\begin{tabular}{|l|c|c|c|}
\hline Periodo & España & Italia & Portugal \\
\hline Dictadura & $59^{\prime} 5$ & $55^{\prime} 6$ & $64^{\prime} 64$ \\
\hline Democracia & 46 '4 & 57 & 63'5 \\
\hline
\end{tabular}

Si analizamos la edad de acceso al cargo de los presidentes de los parlamentos democráticos observamos como la media de edad es similar a la de los presidentes de la dictadura en Portugal e Italia y menor en España. En el caso español se produjo un rejuvenecimiento de la clase política en general, especialmente en los partidos de oposición al franquismo, que también se plasmó en el Parlamento. En el caso de los otros dos países en el inicio de la democracia se recurrió a políticos con dilatadas trayectorias en la oposición a las dictaduras.

Podemos considerar que la edad no es un elemento diferenciador del perfil de los presidentes de las asambleas de las dictaduras y de los parlamentos democráticos, salvo en el caso español, porque el tipo de político experimentado que ocupa esta responsabilidad es similar en ambos periodos. Aunque las opciones político-ideológicas en las que han desarrollado esta experiencia política sean opuestas.

El origen geográfico de los presidentes es diverso en ambos periodos. En España se incrementaron los nacidos en localidades de mayor tamaño en el periodo democrático, y encontramos algunos presidentes nacidos en Madrid. En Italia, aumentaron su presencia los nacidos en Roma frente a los nacidos en las

84 ROSER, M. "Life expectancy". See https://ourworldingdata.org/life-expectancy.

85 Esta media de edad de los presidentes superaba a la de los diputados que era de 52 años, Miguel Ángel Giménez Martínez, Las Cortes españolas en el régimen de Franco. Nacimiento, desarrollo y extinción de una Cámara Orgánica, op. cit., p. 158.

86 Esta media de edad de los presidentes superaba a la de los diputados que era de 50 años, José Manuel Tavares Castilho, "A Assembléia Nacional, 1934-1974: esboço de caracterização", op. cit., p. 74. 
capitales regionales. Y en Portugal, la reducción de los originarios del mundo rural, frente a los otros dos colectivos. En este último caso podemos considerar el mayor apoyo a la dictadura en el mundo rural frente a las ciudades, lo que se reflejó, también, en los presidentes de la Asamblea ${ }^{87}$.

Tabla 2. Origen geográfico de los presidentes de las Asambleas

\begin{tabular}{|l|c|c|c|c|c|c|}
\hline & $\begin{array}{c}\text { España } \\
\text { Dicta. }\end{array}$ & $\begin{array}{c}\text { España } \\
\text { Demo. }\end{array}$ & $\begin{array}{c}\text { Italia } \\
\text { Dicta. }\end{array}$ & $\begin{array}{c}\text { Italia } \\
\text { Demo. }\end{array}$ & $\begin{array}{c}\text { Portugal } \\
\text { Dicta. }\end{array}$ & $\begin{array}{c}\text { Portugal } \\
\text { Demo. }\end{array}$ \\
\hline Capital/Estado & $0 \%$ & $20 \%$ & $0 \%$ & $50 \%$ & $18 \%$ & $14 \%$ \\
\hline Capital/Región & $75 \%$ & $61 \%$ & $60 \%$ & $0 \%$ & $0 \%$ & $57 \%$ \\
\hline Pueblo & $25 \%$ & $16 \%$ & $40 \%$ & $50 \%$ & $82 \%$ & $29 \%$ \\
\hline
\end{tabular}

En los tres casos no se puede considerar que tuviesen un gran peso las capitales de los estados frente a otro tipo de localidades menores, aunque en España ${ }^{88}$ e Italia se incrementó. Por ello, podemos concluir que los presidentes del parlamento tenían un origen diverso y no concentrado en las capitales de los estados, aunque creció la presencia de las localidades de mayor tamaño, probablemente porque la extracción social de estos personajes se correspondia con actividades ligadas a este tipo de localidades.

Sobre su origen familiar no contamos con una información muy completa. Aunque los datos con los que contamos y la formación superior de la mayoría de ellos nos permiten afirmar que sus familias disfrutaban de una situación acomodada para ambos periodos.

En relación con la formación académica de los presidentes de las dictaduras debemos destacar que todos ellos tenian formación superior, algo bastante común entre los procuradores ${ }^{89}$. En España tres eran licenciados y uno doctor, todos ellos en derecho. En Italia, tres eran licenciados en derecho y el otro militar, que ocupó la presidencia en dos periodos, formado en la Academia de la Marina. Y en Portugal uno era doctor, dos licenciados en derecho y otro ingeniero. Por tanto, predominaba la formación jurídica. En el caso portugués este elevado nivel de formación concordaba con el de los diputados. E1 90\% de los miembros de la Asamblea contaban con formación superior, entre los que destacaban los licenciados en derecho ${ }^{90}$.

87 Este dato concuerda con la extracción geográfica de la media de los diputados de la Asamblea, José Manuel Tavares Castilho, "A Assembléia Nacional, 1934-1974: esboço de caracterização", op. cit., p. 67.

88 En España el porcentaje de procuradores originarios de pueblos (42'5\%) era mayor que el de los presidentes y por tanto eran menos los originarios de capitales de provincia o Madrid (57'5\%), Miguel Ángel Giménez Martínez, Las Cortes españolas en el régimen de Franco. Nacimiento, desarrollo y extinción de una Cámara Orgánica, op. cit., p. 158.

$89 \mathrm{El}$ 63\% de los procuradores habían cursado estudios superiores, Miguel Ángel Giménez Martínez, Las Cortes españolas en el régimen de Franco. Nacimiento, desarrollo y extinción de una Cámara Orgánica, op. cit., p. 159.

90 José Manuel Tavares Castilho, A Assembleia Nacional (1934-1974), op. cit., p. 288. 
En relación con los presidentes democráticos analizados, todos ellos, salvo uno del que no tenemos datos, eran titulados universitarios y el $41 \%$ de ellos eran doctores. Lo cual evidencia una formación por encima de la media de todos los países y que se puede comprender por su extracción social acomodada. En cuanto a los estudios universitarios realizados destaca el derecho, que cursaron el 56\% de los personajes estudiados. En segundo lugar estaban los estudios de humanidades, el 28\%. Y finalmente otros estudios (Economía, Medicina o Ingenieria) el 16\%.

La profesión desempeñada por los primeros, en general, concordaba con sus estudios. En España encontramos dos abogados del Estado, un Catedrático de Universidad y un propietario ${ }^{91}$. En Italia, un militar, dos profesionales del derecho y un periodista. En Portugal, dos Catedráticos de Universidad, un Magistrado y un propietario ${ }^{92}$. La excepción eran los propietarios, que no ejercian su profesión, y el periodista, que desarrollaba esta actividad ligada a su actividad política. En este último caso era un hombre del Partido.

Entre los diputados portugueses destacaban los abogados, profesores universitarios, funcionarios, médicos, farmacéuticos y militares ${ }^{93}$, lo que concordaba con la actividad de sus presidentes.

La profesión desempeñada por los presidentes democráticos concordaba con sus estudios. Los licenciados en derecho se dedicaban fundamentalmente a la abogacía, a la enseñanza y a la función pública. El resto ejercían como médicos, ingenieros, etc.

La profesión concordaba con la formación y nos indicaba que eran personas de familia acomodada que a su vez desempeñaban profesiones que les garantizaban una situación socio-económica similar.

Los presidentes de las asambleas de las dictaduras iniciaron su carrera politica con anterioridad al acceso a esta responsabilidad y desempeñaron un papel relevante en los partidos únicos durante las dictaduras.

Entre los presidentes de las dictaduras en España todos ellos habían ocupado relevantes cargos políticos con anterioridad en los diferentes niveles de la administración y cargos de responsabilidad en el Partido Único ${ }^{94}$. En relación

91 E1 27’3\% de los procuradores eran abogados y el 6'4\% catedráticos de universidad, Miguel Ángel Giménez Martínez, Las Cortes españolas en el régimen de Franco. Nacimiento, desarrollo y extinción de una Cámara Orgánica, op. cit., p. 159.

92 En este caso los presidentes no formaban parte del grupo mayoritario de la Asamblea, que eran los abogados y notarios, José Manuel Tavares Castilho, "A Assembléia Nacional, 1934-1974: esboço de caracterização", op. cit., pp. 76-78.

93 José Manuel Tavares Castilho, A Assembleia Nacional (1934-1974), op. cit., pp. 288-289.

94 Esteban Bilbao había desempeñado cargos en todos los niveles de la administración: concejal, Presidente de la Diputación, diputado, senador, ministro y miembro de la Junta Política de FET de las JONS. Antonio Iturmendi fue concejal, gobernador civil, director general, subsecretario, ministro y Consejero de FET de las JONS. Alejandro Rodríguez de Valcárcel fue gobernador civil, ocupó altos cargos en el gobierno y fue Vicesecretario general del Movimiento. Finalmente, Torcuato Fernández Miranda había desempeñado el cargo de Rector, en aquel momento de nombramiento gubernamental, el de director general y Ministro-Secretario general del Movimiento. 
con su origen ideológico 95 encontramos diferencias entre ellos. Por una parte, Esteban Bilbao y Antonio Iturmendi habian militado en el tradicionalismo antes del franquismo y se incorporarán a la nueva FET de las JONS sin cuestionar la unificación. Alejandro Rodríguez de Valcárcel militó en Falange desde 1935 y también asumió sin críticas la unificación. Por último, Torcuato Fernández Miranda se movió en el mundo de las asociaciones de jóvenes católicos y también se incorporó al Movimiento. A la luz de estos datos el origen político de los presidentes no representaba el peso de las diferentes familias del franquismo en las Cortes. Por tanto, podemos afirmar que lo que llevó a la presidencia a estas personas no fue su origen político, sino su fidelidad absoluta al régimen.

Un segundo elemento importante a destacar es el papel de estas personas en la guerra civil. Es conocida la relevancia de la guerra en la biografia política de buena parte de los cargos del franquismo, dado su valor como elemento fundacional del régimen. En este caso dos de ellos Alejandro Rodríguez de Valcárcel y Torcuato Fernández Miranda fueron combatientes. Esteban Bilbao fue prisionero en Bilbao y recuperó la libertad gracias a que fue canjeado por el Alcalde de Bilbao, Ernesto Ercoreca, encarcelado por los rebeldes ${ }^{96}$. Desconocemos el papel de Antonio Iturmendi en la guerra, aunque su hermano Pedro fue combatiente. Él, dada su edad, probablemente desempeñó tareas en retaguardia. Todos ellos habian contribuido al esfuerzo bélico y por tanto a la creación del régimen.

En Italia todos los presidentes habían sido diputados, altos cargos en el Gobierno, Ministros y varios de ellos altos cargos en el PNF97. Un segundo elemento a tener en cuenta en su trayectoria politica es su participación en la I Guerra Mundial en la que combatieron todos menos uno de ellos ${ }^{98}$ y sin duda fue un fundamento para impulsar el nacionalismo que les aproximó al fascismo.

En Portugal, el perfil es similar. Son personas que ocuparon importantes cargos como parlamentarios, Ministros y cargos en el Partido ${ }^{99}$. Algo diferente fue

95 Los procuradores procedentes del falangismo suponian el 46\% $7 \%$ del total, los procedentes de las asociaciones católicas el 4'6\% del total y los del tradicionalismo el 3\% del total, Miguel Ángel Giménez Martínez, Las Cortes españolas en el régimen de Franco. Nacimiento, desarrollo y extinción de una Cámara Orgánica, op. cit., pp. 156-157.

96 Autor, 2002, p. 329.

97 Antonio Casertano había sido alcalde, diputado y subsecretario. Giovanni Giuriati había sido diputado y ministro y después de su paso por la presidencia del parlamento fue Secretario General del PNF. Costanzo Ciano y Dino Grandi habían sido diputados, ocupado altos cargos en el Gobierno, entre ellos el de Ministro y desempeñado cargos en el PNF.

98 Antonio Casertano era demasiado mayor para participar en la I Guerra Mundial, aunque si lo hicieron sus dos hijos uno herido y el otro muerto en combate. Giovanni Giuriati combatió y fue herido en la I Guerra Mundial por lo que fue condecorado en dos ocasiones. Tras el conflicto participó en el movimiento para reclamar el Fiume, junto a Gabriele D’Annunzio. Costanzo Ciano combatió en la Marina italiana en la I Guerra Mundial por lo que recibió cuatro condecoraciones. Dino Grandi combatió en la I Guerra Mundial.

99 Albino Soares Pinto dos Reis Júnior había sido Magistrado, miembro del Tribunal Supremo y del Consejo de Estado, diputado, gobernador, ministro y había desempeñado cargos en la União Nacional. Mário de Figueiredo, amigo personal de Salazar, había sido parlamentario, miembro de comisiones gubernamentales, ministro y había desempeñado cargos en la União Nacional. Por último, Carlos Monteiro do Amaral Neto había desempeñado cargos municipales, en el Gobierno y había desempeñado cargos en la União Nacional. 
el caso de José Alberto dos Reis, el primer presidente de la Asamblea, que había sido Vicerrector de la Universidad de Coimbra y amigo personal de Salazar, por lo que fue nombrado miembro del Consejo Político Nacional (1931) y del Consejo de Estado (1933). Jose Manuel Tavares Castilho señala que entre los diputados de la Asamblea fue perdiendo relevancia su perfil politico-ideológico previo, es decir su militancia católica o monárquica, y la fidelidad al dictador y al régimen se fue convirtiendo en el elemento más relevante ${ }^{100}$. Este último elemento, la fidelidad al dictador, parece que también tuvo una especial relevancia en el caso de algunos de los presidentes como José Alberto dos Reis o Mário de Figueiredo.

\section{Tabla 3. Carrera política previa antes de ocupar}

\section{la presidencia de los presidentes democráticos}

\begin{tabular}{|l|c|c|c|}
\hline Periodo & España & Italia & Portugal \\
\hline Instituciones subestatales & $33 \%$ & $0 \%$ & $28 \%$ \\
\hline Parlamento estatal & $17 \%$ & $43 \%$ & $0 \%$ \\
\hline Gobierno del Estado & $50 \%$ & $57 \%$ & $28 \%$ \\
\hline Otros & $0 \%$ & $0 \%$ & $42 \%$ \\
\hline
\end{tabular}

En cuanto a los presidentes de los parlamentos democráticos el tipo de actividad varía en cada país. En primer lugar, en el caso español y portugués hay que tener en cuenta que dada la duración de las dictaduras los parlamentarios de partidos de la oposición a las dictaduras dificilmente podían contar con experiencia parlamentaria previa. A pesar de ello en Italia contaron con algún parlamentario con experiencia previa al fascismo y posteriormente los presidentes de la Cámara lo fueron tras su labor en las primeras legislaturas democráticas. Este también fue el caso español. También es destacable el porcentaje que habian ocupado cargos en los gobiernos o habian desempeñado responsabilidades delegadas por el Gobierno. Continuaron teniendo un peso importante, especialmente en Portugal y España, los presidentes que habian tenido una experiencia previa en las instituciones subestatales (municipio, provincia, región).

Dentro del apartado de la actividad politica previa a ocupar la presidencia del parlamento debemos destacar la participación en la oposición al fascismo de cuatro de los cinco presidentes del parlamento italiano analizados ${ }^{101}$, en la oposición a la dictadura portuguesa de cinco de los siete presidentes del parlamento portugués y en la oposición a la dictadura franquista de cuatro de los cinco del parlamento español.

La duración en el cargo también marca una importante diferencia entre los dos periodos estudiados. En España la presidencia de las Cortes orgánicas se prolongaba de manera importante. La media de tiempo de ocupación de la presidencia fue de más de 8 años (103 meses), con un máximo de 22 años y

100 José Manuel Tavares Castilho, A Assembleia Nacional (1934-1974), op. cit., pp. 289-291.

101 Una reflexión sobre la relación entre Resistencia y Constitución en Italia en Giacomo Delledonne, "La Resistenza in Assemblea Costituente e nel testo costituzionale italiano del 1948", Historia constitucional, $\mathrm{n}^{\circ}$ 10, 2009, pp. 217-241. 
medio del primer presidente y de un año y siete meses del último. Frente a ello los presidentes de la democracia, salvo uno, ocuparon la presidencia durante una legislatura, que en las Cortes Constituyentes no llegó a los dos años, en los dos siguientes presidentes fueron 3 años y ocho meses y el último del periodo analizado es el que prolongó más su mandato, porque repitió en tres legislaturas, lo que le llevó a ocupar el cargo algo menos de diez años. En Portugal los presidentes de la asamblea de la dictadura repitieron en el cargo prolongando su mandato 4 años y 5 meses, en el más breve, y 16 años en el más longevo. Mientras en el parlamento democrático solamente hubo una repetición en el cargo y los mandatos fueron mucho más breves. El más corto de 7 meses y el más largo de 2 años y 5 meses. En Italia, los presidentes del periodo fascista ocuparon la presidencia durante un periodo medio de 41'8 meses. Todos ellos ocuparon la presidencia durante un periodo prolongado, que va de los 44 a los 58 meses. La excepción fue el segundo mandato de C. Ciano, que únicamente duró 2 meses por su fallecimiento. En el periodo democrático hubo diferencias importantes entre unos y otros presidentes. Entre los siete meses del segundo y los 62 del cuarto.

El comportamiento de España y Portugal es similar. Con unos prolongados mandatos en el periodo de las dictaduras y mucho más breves en el democrático, porque la presidencia está sometida a los cambios de mayorías y no a la voluntad del dictador. En el caso italiano, el modelo es similar, pero dada la mayor brevedad de la vida de la Cámara, el contraste resulta menor.

En cuanto a la continuación de la carrera política de los presidentes, la primera conclusión que podemos extraer es que la presidencia de las asambleas de las dictaduras, en la mayoría de los casos suponía la culminación de su carrera politica. En España Esteban Bilbao se jubiló tras su cese en 1965 y los otros tres presidentes continuaron en política, dos como procuradores y el último como senador de designación real ${ }^{102}$. Teniendo en cuenta la escasa relevancia de estas actividades podriamos considerar que entraron en una especie de retiro, como sucedía con una parte de los senadores en la Restauración. En Italia la situación fue diferente. Los dos primeros presidentes continuaron su actividad en el Senado y uno de ellos como Secretario General del PNF. El siguiente, C. Ciano, falleció en el ejercicio de su cargo y su sucesor concluyó su mandato con la caída del fascismo. En Portugal, el primero de los presidentes, el que tenía una menor implicación institucional previa a ocupar su cargo, continuó ejerciendo como abogado, el segundo permaneció como diputado, el tercero falleció y el cuarto cesó por la Revolución.

Podemos concluir que el ejercicio de la presidencia de las asambleas suponía el final de la trayectoria politica de la mayoría de estas personas o su continuidad en cargos de menor relevancia.

Esta cuestión supone un gran contraste con los presidentes de los parlamentos democráticos, dado que todos ellos continuaron en la actividad política.

102 Es el caso de Torcuato Fernández Miranda, que a pesar de haber tenido un destacado papel en el paso de las Cortes franquistas al Parlamento democrático, su actividad en las Cortes Constituyentes no fue muy relevante, al no formar parte de ninguno de los partidos representados en el Senado. Inicialmente formó parte del grupo parlamentario de la UCD (26.07.197730.07.1978), pero dadas sus discrepancias pasó al Grupo Mixto (31.07.1978-2.01.1979). Información recogida en www.senado.es. 


\section{Tabla 4. Continuidad en la vida politica tras ocupar}

\section{la presidencia de los presidentes democráticos}

\begin{tabular}{|l|c|c|c|}
\hline Periodo & España & Italia & Portugal \\
\hline Instituciones subestatales & $0 \%$ & $0 \%$ & $0 \%$ \\
\hline Parlamento estatal & $0 \%$ & $40 \%$ & $50 \%$ \\
\hline Gobierno del Estado & $60 \%$ & $33 \%$ & $50 \%$ \\
\hline Otros & $40 \%$ & $27 \%$ & $0 \%$ \\
\hline
\end{tabular}

Un porcentaje importante continuaron como parlamentarios, bien como diputados o como senadores, salvo en España. También es importante el número de presidentes que posteriormente fueron ministros o desempeñaron cargos de nombramiento gubernamental en España, Portugal e Italia. Por último, es importante resaltar que en el caso italiano algunos presidentes del parlamento continuaron su carrera politica como presidentes de la República (27\%).

Todo ello nos permite afirmar que la presidencia del Parlamento en estos países no era un cargo en el que concluía la vida política, sino que era un paso más en la carrera politica de estos personajes.

\section{CONCLUSIONES}

Una buena parte de las dictaduras europeas del siglo XX en la definición de su sistema político crearon asambleas que rompieron con la tradición parlamentaria liberal y democrática anterior. Estas asambleas no se basaban en el principio de la división de poderes como los parlamentos liberales y democráticos, sino que partían del principio de un poder único y la coordinación o división de funciones ${ }^{103}$, por lo que la asamblea estaba sometida a la voluntad del dictador. Este modelo de asamblea fue compartido en diferentes países europeos en el periodo de entreguerras, entre los que se encontraban Italia, Portugal y España. En palabras de F. Mohrhoff la asamblea devolvía parte de sus poderes al Ejecutivo debilitando el sistema de división de poderes y convirtiéndose en un instrumento del sistema totalitario ${ }^{104}$. Esta afirmación referida al caso italiano se puede hacer extensiva a otros países europeos como España. Consecuencia de la sustitución del principio de la división de poderes por el de la división de funciones fue la falta de control al gobierno por parte de la asamblea.

En los tres países analizados observamos algunas diferencias relevantes. En España se creó una asamblea corporativa ex novo en el proceso de organización del nuevo estado franquista. En el caso italiano se desarrolló un proceso de "deconstrucción" del parlamento liberal que concluyó con su transformación en

103 Enrico D'Alfonso, Ministro e Presidente della Camera dei fasci e delle corporazioni, op. cit., p. 6 y Miguel Ángel Giménez Martínez, Las Cortes españolas en el régimen de Franco. Nacimiento, desarrollo y extinción de una Cámara Orgánica, op. cit., p. 62.

104 Federico Mohrhoff, Introduzione ad uno studio sugli aspetti storico-politici, giuridicocostituzionali e regolamentari-consuetudinari dell'Istituto presidenziale del Parlamento italiano (18481963), op. cit., p. 13. 
una asamblea corporativa. Por último, en Portugal se mantuvieron algunos elementos formales de los parlamentos liberales, como las elecciones o la capacidad de autorregulación de la asamblea. A pesar de ello en los tres países, las dictaduras, contaron con una asamblea absolutamente leal a los principios de la dictadura gracias al control de los nombramientos o de la elección de sus componentes.

En el nuevo modelo de asamblea la presidencia respondía a una caracterización diferente a la de los parlamentos anteriores y posteriores, tanto en el sistema de elección como en sus funciones. El modelo de presidencia consagraba un presidente representante del Gobierno frente a la Cámara, en vez de un representante de la Cámara frente al Gobierno.

El sistema de elección, en Italia y España, ligaba al Presidente a la voluntad del dictador. La opinión de la cámara era irrelevante. En el caso portugués, aunque elegido por la Cámara, también nos encontramos con un modelo de presidencia ligado al dictador, en algunos casos incluso por una relación personal.

La confianza directa en los presidentes de estas asambleas era clave para convertirlas en un órgano de apoyo político y de resonancia de las políticas de la dictadura. No se crearon para debatir los proyectos o controlar al Gobierno sino para apoyar sus politicas, ofreciendo una imagen de asambleas representativas de los verdaderos intereses de la sociedad, que siempre concordaban con los proyectos del Gobierno.

El presidente de estas asambleas se configuró como un verdadero órgano unipersonal de dirección de la asamblea, con un peso reducido de la mesa de la cámara, algo que contrasta enormemente con las funciones que tendrán los órganos colectivos de los parlamentos en los sistemas democráticos de la segunda mitad del siglo XX, en los que los órganos colectivos de dirección del parlamento, Mesa y Junta de Portavoces, asumen una parte de las tareas que anteriormente habia desempeñado la Presidencia.

La duración del mandato no estaba limitada y por ello, la prolongación de los presidentes en su cargo dependía de la decisión de los dictadores. A fin de cuentas eran sus delegados en la Cámara y no los líderes de la misma.

Entre las funciones que desempeñaba el presidente observamos un fortalecimiento de las mismas, especialmente en la dirección de los trabajos parlamentarios. Algunos ejemplos serian su facultad de nombrar los miembros de las comisiones y a sus presidentes, su participación en el proceso de tramitación de las iniciativas o la capacidad de interpretar el reglamento. Este control de la labor del parlamento por la presidencia garantizaba una absoluta sintonía con la voluntad del gobierno y de sus politicas.

Si observamos la labor de estas asambleas no encontramos con nitidez el desarrollo de la función legislativa habitual en cualquier sistema parlamentario. En España, Franco contaba con este poder y en Italia, el Duce podía decidir el orden del día de la asamblea, lo que limitaba su capacidad de decisión en este ámbito.

Si observamos el perfil de los personajes analizados podemos afirmar que tenían algunos elementos comunes y otros diferentes si comparamos el periodo de las dictaduras con el de las democracias posteriores. 
El origen geográfico y social, la formación, la profesión no diferian entre un periodo y otro. La edad de acceso al cargo era diferente únicamente en el caso español. En todos los casos nos encontramos con familias de clase media o acomodadas que ofrecian a sus hijos una buena formación universitaria, especialmente jurídica, que les daba acceso a trabajos cualificados ligados al mundo del derecho.

Todos ellos contaban con una importante experiencia política previa, aunque no fuese la misma en los dos grupos analizados. En un caso eran personas ligadas a las estructuras políticas de las dictaduras (instituciones y Partido) y en el otro, en la mayoría de los casos, a la oposición a las dictaduras, a la que dieron continuidad en las nuevas instituciones democráticas. Por tanto, nos encontramos con políticos experimentados pero en actividades opuestas de la vida pública: personajes leales a las dictaduras y opositores a las mismas, en buena parte de los casos.

La duración de los mandatos en la presidencia también nos muestra un contraste importante entre los dos periodos. Mientras las asambleas de las dictaduras nos ofrecian unas presidencias ligadas a la voluntad del dictador, ajena a la Cámara, en la que la duración del mandato dependía del mantenimiento de la confianza en el designado, en los parlamentos democráticos los mandatos se acortaron y dependian de la configuración de las mayorias parlamentarias y de la duración de las legislaturas.

Tras su paso por la presidencia de la asamblea los presidentes de las dictaduras se retiraron o tuvieron una actividad que podemos considerar de baja intensidad politica. Por el contrario, los presidentes democráticos, en su mayoría, continuaron con una intensa actividad politica, alcanzando en algunos casos puestos gubernamentales o la propia Presidencia de la República, en el caso italiano.

En conclusión, el contraste entre la presidencia de las asambleas de las dictaduras y de los parlamentos democráticos responde a la diferente concepción de estos órganos en el sistema político de esos países. En las dictaduras los presidentes tenían la función de controlar la cámara para el Gobierno y eran absolutamente independientes de la asamblea. Por ello eran personas de plena confianza politica de los dictadores, con experiencia institucional previa en la que habian mostrado su fidelidad, y desarrollaron este último servicio como delegados del Gobierno en estas asambleas. Por el contrario, en los parlamentos democráticos, los presidentes estaban ligados a la mayoría gubernamental que se había conformado de acuerdo con la voluntad del electorado y no de un dictador. También era personas con una importante experiencia política, pero en la mayoría de los casos en la oposición a las dictaduras. Y no concluían su vida política como presidentes, sino que esta responsabilidad era una más, aunque destacada, en su trayectoria, que en la mayoría de los casos continuó en diferentes instituciones del Estado.

\section{BIBLIOGRAFÍA}

Albert, Carl, The office and the duties of the Speaker of the House of Representatives, Washington, U.S. Govt. Print. Off., 1976. 
Almeida de Carvalho, Rita, A Assembleia Nacional no pos-guerra (1945-1949), Assembleia da República, Lisboa, 2002.

Bonini, Francesco, "Présidents et bureaux de présidence de la Chambre italienne sous le fascisme (1922-1939)", en Parlamentos: a lei, a prática e as representações. Da Idade Media à Actualidade / Parliaments: the Law, the practice and the representations. From the Middle Ages to the Present Day", Assembleia da República - Universidade de Coimbra, Lisboa, 2010, pp. 449-453.

Braga da Cruz, Manuel e António Costa Pinto, Dicionário biográfico parlamentar (1935-1974), Assembleia da República, Lisboa, 2005, 2 vols.

Bulst, Neithard, "Prosopography and the Computer: Problems and Possibilities", History and Computing, vol. II, 1989, pp. 13-18.

Buonomo, Giampiero, "La decadenza dei Deputati nella Camera del Regino d'Italia del 9 novembre 1926", Historia constitucional, $\mathrm{n}^{\circ}$ 13, 2012, pp. 697-715

Cano Bueso, Juan, "El principio de autonormatividad de las cámaras y la naturaleza jurídica del reglamento parlamentario", Revista de Estudios Politicos, $\mathrm{n}^{\circ}$ 40, 1984, pp. 85-99.

D’Alfonso, Enrico, Ministro e Presidente della Camera dei fasci e delle corporazioni, Alberto Morano Ed., Napoli, 1940.

Daudet, Yves, La Présidence des Assemblées parlementaires françaises, Presses Universitaires de France, Paris, 1965.

De Miguel Barcena, Josu, "El reglamento parlamentario en los orígenes del constitucionalismo europeo y español”, Historia constitucional, $\mathrm{n}^{\circ} 17$, 2016, pp. 55-81.

Delledonne, Giacomo, "La Resistenza in Assemblea Costituente e nel testo costituzionale italiano del 1948”, Historia constitucional, $\mathrm{n}^{\circ}$ 10, 2009, pp. 217241.

Di Napoli, Mario, "Camera dei Deputati”, en Victoria de Grazia e Sergio Luzzato (a cura di), Dizionario del fascismo, Einaudi, Torino, 2002, vol. I, pp. 218221.

Di Napoli, Mario, "Camera dei fasci e delle corporazioni", en Victoria de Grazia e Sergio Luzzato (a cura di), Dizionario del fascismo, Einaudi, Torino, 2002, vol. I, pp. 221-224.

Di Napoli, Mario, "Senato del Regno", en Victoria de Grazia e Sergio Luzzato (a cura di), Dizionario del fascismo, Einaudi, Torino, 2003, vol. II, pp. 618-621.

Diccionario biográfico de los parlamentarios de Vasconia (1876-1939), Parlamento Vasco, Vitoria-Gasteiz, 2007, 3 vols.

Diccionario Biográfico Español (http://dbe.rah.es/).

DIZIONARIO biografico degli italiani. (http: / / www.treccani.it/biografico).

Domper Lasús, Carlos, Dictatorship and the Electoral Vote. Francoism and the Portuguese New State Regime in Comparative Perspective. 1945-1975, Sussex Academic Press, Brighton-Chicago-Toronto, 2020.

Fernández Sarasola, Ignacio, Reglamentos parlamentarios (1810-1977), Iustel, Madrid, 2012. 
Follet, Mary P. The Speaker of the House of Representatives, Longmans, Green and Co., New York, 1896.

Furlani, Silvio et alii, I Presidenti della Camera, Editalia, Roma, 1988.

Garrigues, Jean (dir.), Les Présidents de l'Assemblée nationale de 1789 à nos jours, Classiques Garnier, Paris, 2015.

Gianfrancesco, Eduardo, "Parlamento e regolamenti parlamentari in epoca fascista”, Osservatorio sulle fonti, $\mathrm{n}^{\circ}$ 2, 2008, pp. 1-32.

Giménez Martínez, Miguel Ángel, Las Cortes españolas en el régimen de Franco. Nacimiento, desarrollo y extinción de una Cámara Orgánica, Congreso de los Diputados, Madrid, 2012.

Hitchner, Dell G., "The Speaker of the House of Representatives", Parliamentary Affairs, XIII December, 1959, pp. 185-197.

Jerónimo Sánchez-Beato, Estefanía y Miguel Ángel Morales Payán, De las Cortes Españolas al Congreso de los Diputados: el devenir de su presidencia (194278), Universidad de Almería, Almería, 2005.

Jerónimo Sánchez-Beato, Estefanía y Miguel Ángel Morales Payán, La presidencia de las Cortes en el constitucionalismo histórico español, Universidad de Almeria, Almería, 2004.

Jerónimo Sánchez-Beato, Estefanía, La Presidencia del Congreso de los Diputados en el sistema constitucional español de 1978, Ayuntamiento de Málaga, Málaga, 2006.

Keats-Rohan, Katharine S.B., "Prosopography and Computing: a Marriage made in Heaven?", History and Computing, vol. 12-1, 2000, pp. 1-11.

Laundy, Philip, The Office of Speaker, Cassell \& Co. Ltd., London, 1964.

Laban, Matthew William, The Speaker of the House of Commons: The Office and Its Holders since 1945, PhD Thesis - University of London, London, 2014

Mohrhoff, Federico, Introduzione ad uno studio sugli aspetti storico-politici, giuridico-costituzionali e regolamentari-consuetudinari dell'Istituto presidenziale del Parlamento italiano (1848-1963), Editore Colombo, Roma, s.d.

Palonen, Kari, "Thinking of Politics in a Parliamentary Manner. Perspectives on the Conceptual History of Parliamentarism", en Pasi Ihalainen, Cornelia Ilie, Kari Palonen (eds.), Parliament and Parliamentarism. A comparative History of a European Concept, Berghahn, New York - Oxford, 2016, pp. 228-242.

Perfetti, Francesco, La Camera dei fasci e dei corporazioni, Bonacci Editore, Roma, 1991.

Peters, Ronald M. Jr. (ed.), The speaker: leadership in the U.S. House of Representatives, Washington D.C, Congressional Quarterly, 1995.

Roser, M. "Life expectancy". See https://ourworldingdata.org/lifeexpectancy.

Schijvenaars, Toine, "Computerized Prosopographical Research", en Koen Goudriaan, Kees Mandemakers, Jogchum Reitsma, Peter Stabel (eds.) Prosopography and Computer. Contributions of Mediaevalists and Modernists on the Use of Computer in Historical Research, Leuven, 1995, pp. 1-24. 
Schmitter, Phillipe C., Portugal: do Autoritarismo à Democracia, Instituto de Comunicação Social, Lisboa, 1999.

Seaward, Paul (ed.), Speakers and the Speakership. Presiding Officers and the Management of Business from the Middle Ages to the 21st Century, Parliamentary History, Oxford, 2010.

Séguin, Pierre, 240 dans un fauteuil. La saga des présidents de l'Assemblée, Éditions du Seuil, Paris, 1995.

Sicardi, Stefano, "Il fascismo in Parlamento: lo svuotamento della rappresentanza generale", en Luciano Violante (ed.), Storia d'Italia. Annali 17. Il Parlamento, Einaudi editore, Torino, 2001, pp. 253-290.

Sotinel, Claude, "Prosopographie et biographie", en Problemes \& Methodes de la biographie. Actes du Colloque (Sorbonne, 3-4 mai 1985), Paris, 1985, pp. 149151.

Stone, Lawrence, El pasado y el presente, FCE, México, 1986.

Tavares Castilho, José Manuel, “A Assembleia Nacional, 1934-1974: esboço de caracterização", Penélope: revista de história e ciências sociais, $n^{\circ} 24,2001$, pp. 65-84.

Tavares Castilho, José Manuel, A Assembleia Nacional (1934-1974), Tese submetida como requisito parcial para obtenção do grau de Doutor em História Moderna e Contemporânea, Lisboa, 2007.

Tavares Castilho, José Manuel, Os Deputados da Assembleia Nacional 19351974, Assembleia da República, Lisboa, 2009.

Urquijo, Mikel, "Models of parliamentary speakership in the nineteenth and twentieth centuries: France, Italy, Portugal and Spain”, Parliaments, Estates \& Representation, $\mathrm{n}^{\circ}$ 40-3, 2020, pp. 308-323.

Urquijo, Mikel, "Parliamentary speakership: from individual speakership to the collective direction of parliamentary work", Spanish Journal of Legislative Studies, $\mathrm{n}^{\mathrm{o}} 2$, 2020, artículo 3 .

Urquijo, Mikel, "La Presidencia del Parlamento en el marco de las revoluciones liberales del sur de Europa”, en Vital Moreira y José Domingues (coord.), Dois Séculos de Constitucionalismo Eleitoral (1820-2020): Atas da Conferência Internacional, Universidade Lusiada, Lisboa, 2021, pp. 317-346.

Varela Suanzes-Carpegna, Joaquín, Constituciones y leyes fundamentales, Iustel, Madrid, 2012.

Zubrov, Alfred T. (ed.), Speakers of the House 1789-2002, Hauppauge, NY, Novinka Books, 2002.

Enviado el (Submission Date): 05/06/2020

Aceptado el (Acceptance Date): 9/09/2020 